Journal of Organometallic Chemistry, 168 (1979) 251-258

(C) Elsevier Sequoia S.A., Lausanne - Printed in The Netherlands

\title{
THE FORMATION OF LITHIUM DIARYLARGENTATES FROM ARYLSILVER COMPOUNDS AND THE CORRESPONDING ARYLLITHIUM COMPOUNDS
}

J. BLENKERS, H.K. HOFSTEE, J. BOERSMA and G.J.M. VAN DER KERK Laboratory for Organic Chemistry, State University of Utrecht, Utrecht (The Netherlands) (Received September 11th, 1978)

\section{Summary}

Diarylsilverlithium compounds of the type $\mathrm{Ar}_{2} \mathrm{AgLi}$ are formed by treating arylsilver compounds with the corresponding aryllithium compounds. Cryoscopy in benzene shows that the $\mathrm{Ar}_{2} \mathrm{AgLi}$ compounds are associated into dimers. NMR spectroscopic data indicate that only one type of aryl group is present in these dimers, and that each aryl group is bridging between one silver and one lithium atom.

\section{Introduction}

Since organolithium compounds have not been used extensively in the synthesis of arylsilver compounds (in contrast to the situation with arylcopper compounds) the reaction of aryllithium compounds with silver salts or arylsilver compounds has been studied only incidentaily [1,2]. As for copper, it was found in these cases that the aryllithium compounds react with silver salts or with arylsilver compounds to give lithium diarylargentates:

$2 \mathrm{ArLi}+\mathrm{AgX} \rightarrow \mathrm{Ar}_{2} \mathrm{AgLi}+\mathrm{LiX}$

$\mathrm{ArLi}+\mathrm{ArAg} \rightarrow \mathrm{Ar}_{2} \mathrm{AgLi}$

In the special case of bis $\{2$-[(dimethylamino)methyl]phenyl $\}$ silverlithium, in which the substituent at the phenyl ring carries a donor atom, structural conclusions were drawn from molecular weight determinations and NMR spectral data. It was shown that aryl groups bridging between one silver and one lithium atom are present in the dimeric compound, and intramolecular coordination between nitrogen and lithium was suggested [2].

Since in the reactions reported up to now, use was made of aryl groups containing electronically very active substituents, we decided to study the reac- 
tions between arylsilver and aryllithium compounds for the simplest cases, viz. for unsubstituted and methyl-substituted phenyl groups.

\section{Results and discussion}

When a diethyl ether solution of one equivalent of an aryllithium compound was added to a suspension of the corresponding arylsilver compound in toluene at $-40^{\circ} \mathrm{C}$, in all cases colourless solutions were obtained (in some cases the reaction mixture had to be stirred for a few minutes at $0^{\circ} \mathrm{C}$ ). After removing the diethyl ether in vacuo at $-40^{\circ} \mathrm{C}$, white crystals of the argentate appeared upon cooling to $-90^{\circ} \mathrm{C}$.

$\operatorname{ArAg}+\operatorname{ArLi} \frac{\text { toluene } / \mathrm{Et}_{2} \mathrm{O}}{-40^{\circ} \mathrm{C}} \mathrm{Ar}_{2} \mathrm{AgLi}$

Ar = phenyl (I), 2-methylphenyl (II), 3-methylphenyl (III), 4-methylphenyl (IV) and 2,6-dimethylphenyl (V).

The stoichiometry of the compounds followed from the analytical and from NMR spectroscopic data. The white crystals still contained diethyl ether and the NMR spectra indicated that the ether is present in complexed form. However, from the same reaction of 2,6-dimethylphenylsilver with the corresponding lithium compound the product $\mathrm{Ar}_{2} \mathrm{AgLi}$ was obtained free of diethyl ether (Table 1).

It proved impossible to obtain any of the other complexes free of diethyl ether; reactions in the absence of ether are incomplete, and from the ether/ $\mathrm{Ar}_{2} \mathrm{AgLi}$ complexes the ether could not be removed without complete decomposition.

The white crystalline compounds are very sensitive to oxygen and moisture and decompose within a few seconds in air. At room temperature all the compounds decompose slowly. The thermal decomposition temperatures were determined by DTA and are summarized in Table 1. The DTA curve of the diethyl ether complex of bis(2-methylphenyl)silverlithium (II) is shown in Fig. 1 together with that of the diethyl ether complex of diphenylsilverlithium (I). Apart from the exothermic effect occurring for both compounds at $157^{\circ} \mathrm{C}$ and

TABLE 1

SOME CHARACTERISTICS OF DIARYLSILVERIITHIUM COMPOUNDS

\begin{tabular}{|c|c|c|c|c|}
\hline $\begin{array}{l}\text { Compound } \mathrm{Ar}_{2} \mathrm{AgLi} \\
\mathrm{Ar}=\end{array}$ & Stoichiometry & $\begin{array}{l}\text { Molecular } \\
\text { weight (found } \\
\text { (calcd. }{ }^{a} \text { ) }\end{array}$ & $\begin{array}{l}\text { Degree of } \\
\text { association }\end{array}$ & $\begin{array}{l}\text { Decomposition } \\
\text { temperature }{ }^{b} \\
\left.{ }^{\circ} \mathrm{C}\right)\end{array}$ \\
\hline Phenyl (I) & $\mathrm{Ar}_{2} \mathrm{AgLi} \cdot \mathrm{Et}_{2} \mathrm{O}$ & $715(343.2)$ & 2.08 & 102 \\
\hline 2-Methylphenyl (II) & $\mathrm{Ar}_{2} \mathrm{AgLi}-\mathrm{Et}_{2} \mathrm{O}$ & $603(371.2)$ & $1.63 c$ & $157^{d}$ \\
\hline 3-Methylphenyl (III) & $\mathrm{Ar}_{2} \mathrm{AgLi}-\mathrm{Et}_{2} \mathrm{O}$ & $780(371.2)$ & 2.09 & 131 \\
\hline 4-Methylphenyl (IV) & $\mathrm{Ar}_{2} \mathrm{AgLi} \cdot \mathrm{Et}_{2} \mathrm{O}$ & $776(371.2)$ & 2.08 & 171 \\
\hline 2,6-Dimethylphenyl (V) & $A x_{2} A_{B L i}$ & $670(325.1)$ & 2.06 & 191 \\
\hline
\end{tabular}

a Calculated for monomer. $b$ The decomposition temperatures were determined by DTA at a heating rate of $5^{\circ} \mathrm{C} / \mathrm{min}$. $c$ The degree of association was found to be concentration dependent: $1.06(0.3 \%), 1.30$ (0.6\%). $1.90(0.9 \%), 1.95(1.2 \%)$ and $1.96(1.6 \%)$. $d$ The thermogram of this compound also showed an endothermic effect at $133^{\circ} \mathrm{C}$. 

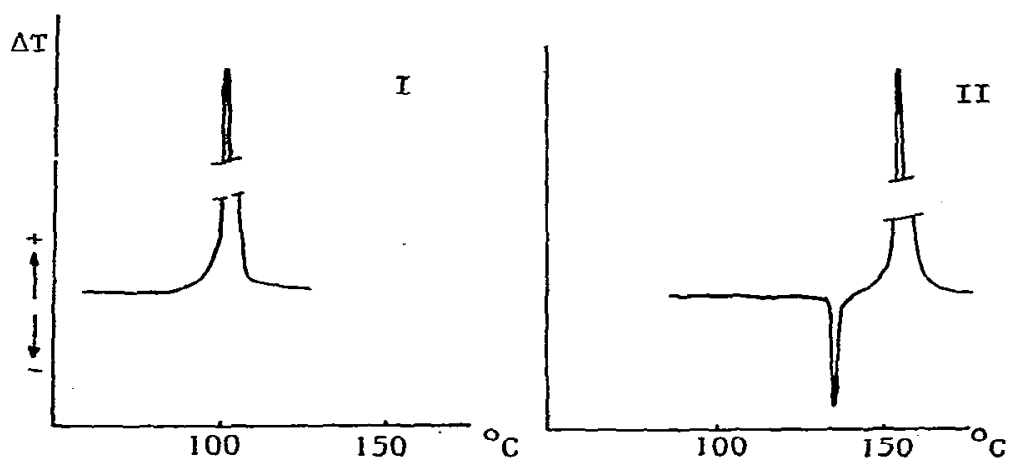

Fig. 1. DTA graphs of the diethyl ether complexes of diphenylsilverlithium (I) and of bis(2-methylphenyl)silverlithium (II).

$102^{\circ} \mathrm{C}$, respectively, for the first compound in addition an endothermic effect was observed at $133^{\circ} \mathrm{C}$. Analysis of compound II after heating in vacuo at about $130^{\circ} \mathrm{C}$ for some minutes proved that it loses ether under these circumstances. The other complexes show exothermic effects only, due to complete decomposition.

The molecular weights of the argentates, determined by means of cryoscopy in benzene, are given in Table 1. All compounds are non-dissociating dimers except the diethyl ether complex of bis(2-methylphenyl)silverlithium (II) which is a dissociating dimer. As discussed above this complex can selectively lose diethyl ether, and the following equilibrium may be responsible for the observed dissociation:

$$
\left[\left(\mathrm{C}_{7} \mathrm{H}_{7}\right)_{2} \mathrm{AgLi} \cdot \mathrm{Et}_{2} \mathrm{O}\right]_{2} \rightleftharpoons\left[\left(\mathrm{C}_{7} \mathrm{H}_{7}\right)_{2} \mathrm{AgLi}\right]_{2}+2 \mathrm{Et}_{2} \mathrm{O}
$$

The IR data of the compounds are listed in Table 2. The spectra show strong absorptions at about $1050 \mathrm{~cm}^{-1}$ due to the asymmetrical $\mathrm{C}-\mathrm{O}-\mathrm{C}$ stretching vibration $\nu(\mathrm{COC})$. From a comparison with the position of free diethyl ether it is evident that the ether is coordinated, as also appears from the NMR data (see later). The spectra show also the expected ring-substitution pattern in the 700$800 \mathrm{~cm}^{-1}$ (cf. Table 2) and in the $1650-2000 \mathrm{~cm}^{-1}$ region.

The absorptions in the $400-500 \mathrm{~cm}^{-1}$ region can be considered as vibrations of the $\mathrm{Ag}_{2} \mathrm{Li}_{2} \mathrm{C}_{4}$ skeleton, and are probably coupled with vibrations of the aryl rings in which the metal substituents move with appreciable amplitude. These

TABLE 2

SOME IR DATA FOR DIARYLSILVERLITHIUM COMPOUNDS

\begin{tabular}{|c|c|c|c|c|c|c|}
\hline \multirow{2}{*}{ 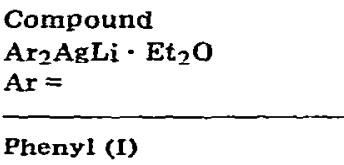 } & \multicolumn{3}{|c|}{$\begin{array}{l}\text { Vibrations of the } \mathrm{Ag}_{2} \mathrm{Li}_{2} \mathrm{C}_{4} \\
\text { skeleton }\end{array}$} & \multicolumn{2}{|l|}{$\gamma(\mathrm{C}-\mathrm{H})$} & $\nu(\mathrm{COC})$ \\
\hline & $459 v s$ & $444 \mathrm{~m}$ & $408 w$ & $722 \mathrm{~s}$ & 707vs & $1048 s$ \\
\hline 2-Methylphenyl (II) & $458 \mathrm{~m}$ & $438 s$ & $389 \mathrm{~m}$ & $740 v s$ & & $1053 s$ \\
\hline 3-Methylphenyl (III) & $465 w$ & $426 s$ & $412 w$ & $764 v s$ & 711vs & $1050 s$ \\
\hline 4-Methylphenyl (IV) & $468 \mathrm{~s}$ & & $418 w$ & 788vs & & $1049 s$ \\
\hline 2,6-Dimethylphenyl (V) & $468 \mathrm{~m}$ & $452 \mathrm{~m}$ & & 782vs & $719 \mathrm{~m}$ & - \\
\hline
\end{tabular}


latter vibrations were designated as $\mathrm{X}$-sensitive by Whiffen [3]. In Table 2 a series of absorptions in the $400-500 \mathrm{~cm}^{-1}$ region is presented. Since interactions of vibrations occur, it would not be justified to propose definite assignments.

The NMR spectra of the compounds were recorded in deuterotoluene at various temperatures. Both ${ }^{1} \mathrm{H}$ and ${ }^{13} \mathrm{C}$ NMR spectra were found to be concentration independent. The spectra of all compounds proved to be temperature dependent in the range -90 to $+20^{\circ} \mathrm{C}$. The NMR spectral data obtained at $-10^{\circ} \mathrm{C}$ are presented in Table 3 , together with those of the parent hydrocarbons. In all cases the following specific observations were made at low temperatures only:

(a) The occurrence of silver-proton couplings.

(b) The occurrence of silver-carbon couplings as well as lithium-carbon

TABIE 3

${ }^{1}$ H AND ${ }^{13} \mathrm{C}$ NMR SPECTRAL DATA $\alpha$ FOR DIARYLSILVERLIHHIUM COMPOUNDS AT - $0^{\circ} \mathrm{C}$ IN DEUTEROTOLUENE AND FOR THE PARENT HYDROCARBONS

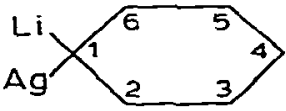

\begin{tabular}{|c|c|c|c|c|c|c|c|}
\hline \multicolumn{8}{|l|}{${ }^{1}$ H NMR spectra $b$} \\
\hline $\begin{array}{l}\text { Compound } \\
\mathrm{Ar}_{2} \mathrm{AgLi} \cdot \mathrm{Et}_{2} \mathrm{O} \\
\mathrm{Ar}=\end{array}$ & $\mathbf{H}^{\mathbf{l}}$ & $\mathbf{H}^{2}$ & $\mathbf{H}^{3}$ & $\mathrm{i}^{4}$ & $\mathbf{H}^{5}$ & $\mathrm{Fi}^{6}$ & $\mathbf{I}\left(\mathrm{CH}_{3}\right)$ \\
\hline Pheny1 & - & 8.20 & 7.15 & 7.02 & 7.15 & 8.20 & - \\
\hline Benzene & 7.38 & 7.38 & 7.38 & 7.38 & 7.38 & 7.38 & - \\
\hline 2-Methylphenyl & - & - & $7.0(\mathrm{br})$ & $7.0(\mathrm{br})$ & $7.0(\mathrm{br})$ & $7.9 / 8.5$ & 2.68 \\
\hline Toluene & $7.2(b r)$ & 一 & $7.2(\mathrm{br})$ & $7.2(b r)$ & 7.2 (br) & $7.2(\mathrm{br})$ & 2.28 \\
\hline 3-Methylphenyl & - & 7.9 (br) & - & 6.97 & 7.21 & 8.07 & 2.18 \\
\hline Toluene & $7.2(b r)$ & $7.2(\mathrm{br})$ & - & $7.2(\mathrm{br})$ & $7.2(b r)$ & $7.2(\mathrm{br})$ & 2.28 \\
\hline 4-Methylphenyl & - & 8.13 & 7.04 & - & 7.04 & 8.13 & 2.14 \\
\hline Toluene & $7.2(\mathrm{br})$ & $7.2(b r)$ & 7.2 (br) & & $7.2(\mathrm{br})$ & 7.2 (br) & 2.28 \\
\hline 2.6-Dimethylphenyl & - & - & $6.6(\mathrm{br})$ & $6.6(b r)$ & $6.6(\mathrm{br})$ & - & $\begin{array}{l}2.8 / 2.7 \\
/ 2.5\end{array}$ \\
\hline 1,3-Xylene & $7.0(b r)$ & 一 & 7.0 (br) & 7.0 (br) & $7.0(\mathrm{br})$ & 一 & 2.29 \\
\hline \multicolumn{8}{|l|}{${ }^{13} \mathrm{C}$ NMR spectra $c$} \\
\hline $\begin{array}{l}\text { Compound } \\
\mathrm{Ar}_{2} \mathrm{AgLi} \cdot \mathrm{Et}_{2} \mathrm{O} \\
\mathrm{Ar}=\end{array}$ & $c^{1}$ & $c^{2}$ & $\mathbf{c}^{3}$ & $c^{4}$ & $c^{5}$ & $c^{6}$ & $\mathrm{C}\left(\mathrm{CH}_{3}\right)$ \\
\hline Phenyl & 160.0 (br) & 144.3 & 128.0 & 127.5 & 128.0 & 144.3 & - \\
\hline Benzene & 128.69 & 128.69 & 128.69 & 128.69 & 128.69 & 128.69 & - \\
\hline 2-Methylphenyl & $162.0(\mathrm{br})$ & 149.4 & 128.0 & 124.1 & 124.6 & 140.7 & 29.1 \\
\hline Toluene & 129.41 & 137.58 & 129.41 & 128.63 & 125.82 & 128.63 & 21.35 \\
\hline 3-Methylphenyl & 157.3 & 144.9 & 134.8 & 122.2 & 128.1 & 141.9 & 23.4 \\
\hline Toluene & 128.63 & 129.41 & 137.58 & 129.41 & 128.63 & 125.82 & 21.35 \\
\hline 4-Methylphenyl & $163.8(\mathrm{br})$ & 141.9 & 127.7 & 134.4 & 127.7 & 141.9 & 22.2 \\
\hline Toluene & 125.82 & 128.63 & 129.41 & 137.58 & 129.41 & 128.63 & 21.35 \\
\hline 2,6-Dimethylphenyl & $d$ & 147.9 & 128.9 & 121.5 & 128.9 & 147.9 & 28.6 \\
\hline I.3-Xylene & 129.61 & 137.21 & 125.84 & 127.88 & 125.84 & 137.21 & 20.86 \\
\hline
\end{tabular}

$a$ The chemical shifts were measured relative to internal TMS. $b$ Ether absorptions: $\left.\left.\mathrm{H}_{(\mathbf{C H}}\right), 2.6: \mathrm{H}_{(\mathrm{CH}}\right), \mathrm{O} .7$ ppm. $c$ Ether absorptions: $\mathrm{C}\left(\mathrm{CH}_{2}\right), 65.6 \mathrm{ppm} ; \mathrm{C}\left(\mathrm{CH}_{3}\right), 14.4 \mathrm{ppm}$. ${ }^{d}$ Not observed. 
couplings on the signal due to the metal-bound carbon atoms.

(c) The appearance of different ortho protons.

(d) The appearance of different methyl peaks.

The phenomena (a) and (b), occurring in compounds I to V, are illustrated for compound $\mathrm{I}$ by the ${ }^{1} \mathrm{H}$ and ${ }^{13} \mathrm{C}$ NMR spectra (Figs. 2 and 3 , respectively).

In the ${ }^{1} \mathrm{H}$ NMR spectrum of compound I at $0^{\circ} \mathrm{C}$ (Fig. 2) the ortho protons appear as a doublet of triplets. Upon cooling, this part of the spectrum broadens and, after coalescence at $-30^{\circ} \mathrm{C}$, at still lower temperatures a triplet of triplets is observed which can only be explained if (in addition to protonproton couplings) silver-proton couplings of about $7 \mathrm{~Hz}$ are present (cf. also ref. 2). $\mathrm{Li}^{1} \mathrm{H}$ couplings were not observed. However, the resolution of the spectra was about $0.5 \mathrm{~Hz}$ and therefore couplings smaller than $0.5 \mathrm{~Hz}$ would pass unobserved.

The ${ }^{13} \mathrm{C}$ NMR spectral data of the compounds $\mathrm{I}$ to $\mathrm{V}$ are shown in Table 3. At temperatures higher than $-30^{\circ} \mathrm{C}$ the signal of $\mathrm{C}^{\mathrm{I}}$ is a rather broad singlet of low intensity. However, at still lower temperatures a doublet of multiplets appears which can only be explained by the presence of ${ }^{107} \mathrm{Ag}-{ }^{13} \mathrm{C},{ }^{109} \mathrm{Ag}-{ }^{13} \mathrm{C}$ and ${ }^{7} \mathrm{Li}-{ }^{13} \mathrm{C}$ couplings as indicated in Fig. 3.

The NMR data indicate that at all temperatures used only one type of aryl group occurs in all argentates investigated, and that this aryl group is simultaneously bonded to one silver and one lithium atom, i.e. the aryl groups are bridging between silver and lithium. In view of these spectral data we propose the structure shown in Fig. 4 for the compounds I to IV. The structure of compound $\mathrm{V}$ would be similar, except for the absence of coordinated diethyl ether. In these structural propositions it is assumed that the diethyl ether molecules are coordinated to lithium. This seems plausible in view of the HSAB principle.

The NMR spectra show no couplings with silver and/or lithium at temperatures above $-30^{\circ} \mathrm{C}$, which is probably due to fast exchange of aryl groups. Since the spectra show no concentration dependence, this exchange must be intramolecular. At low temperatures the ${ }^{1} \mathrm{H}$ NMR spectra of the ether-free bis[2,6-
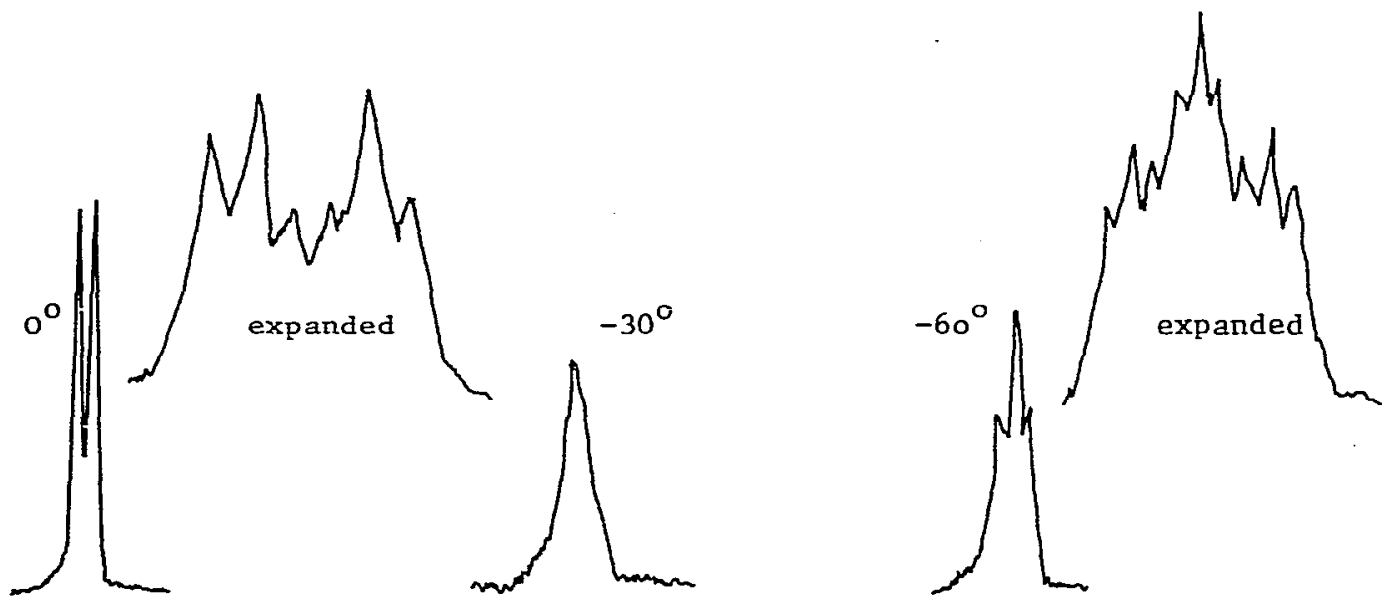

Fig. 2. ${ }^{1}$ H NMR spectra (ortho-proton region) of the diethyl ether complex of diplienylsilverlithium (I). 


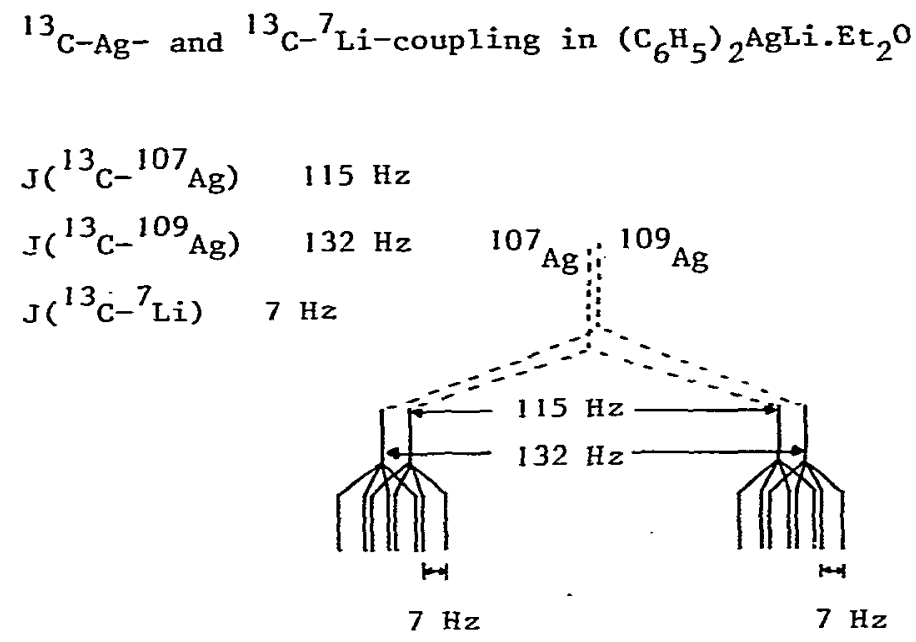

Fig. 3. The low-field region $\left(C^{1}\right)$ of the ${ }^{13} \mathrm{C}$ NMR spectrum of the diethyl ether complex of diphenyisilverlithium (I) at $-78^{\circ} \mathrm{C}$.

dimethylphenyl]silverlithium (compound V) show the presence of at least three magnetically unequivalent methyl groups (Fig. 5). Since the phenyl group is symmetrically substituted the observed unequivalence cannot be accounted for by configurational isomerism arising from hindered rotation of the aryl groups in a flat structure. Therefore, this observation can only be explained by assuming that the $\mathrm{Ag}_{2} \mathrm{Li}_{2} \mathrm{C}_{4}$ ring system is non-planar. Since the silver atoms will be linearly coordinated, certainly so in the absence of external ligand molecules, chair, boat or twisted configurations of this ring system may occur.

It is easily seen from model studies that in all configurations magnetically unequivalent sets of methyl groups exist. Similar observations were made for the diethyl ether complex of diphenylsilverlithium (I). The ${ }^{1} \mathrm{H}$ NMR spectra of this
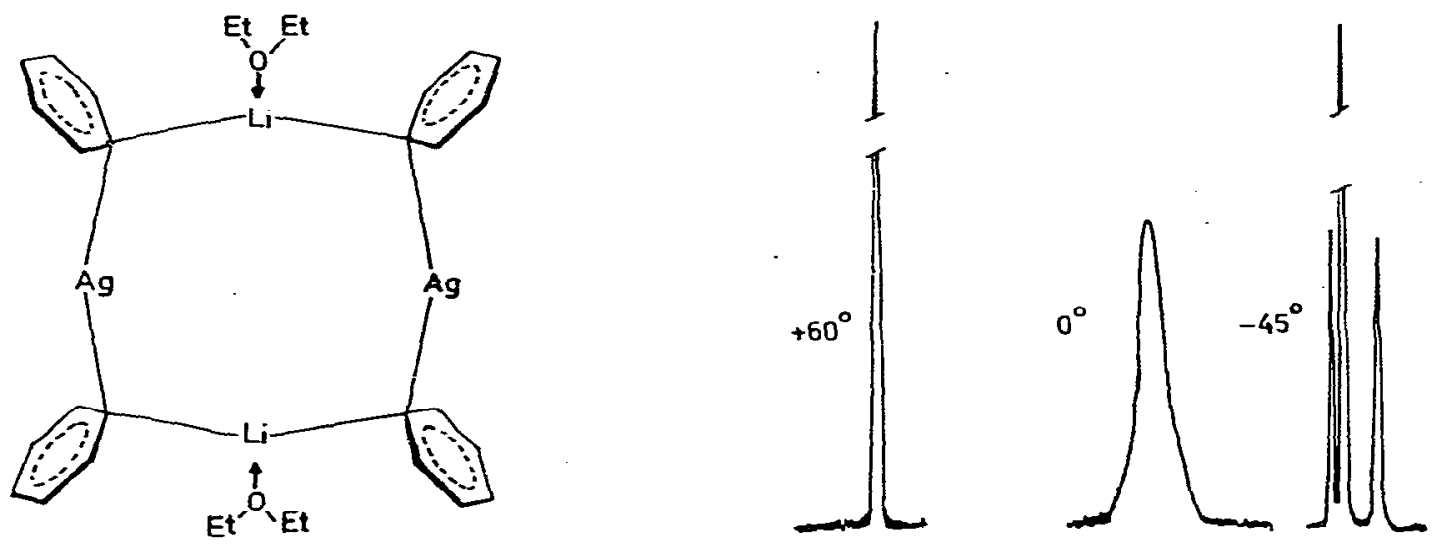

Fig. 4. Structure proposed for compounds of the type $\left[\mathrm{Ar}_{2} \mathrm{AgLi}-\mathrm{Et}_{2} \mathrm{O}\right]_{2}$.

Fig. 5. ${ }^{1}$ H NMR spectra (ortho-proton region) of the diethyl ether complex of diphenylsilverlithium (I) at -60 and $-90^{\circ} \mathrm{C}$. 

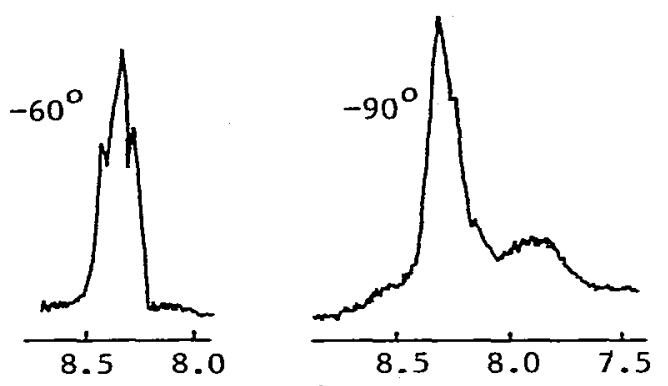

Fig. 6. ${ }^{1} \mathrm{H}$ NMR spectra (ortho-proton region) of the diethyl ether complex of diphenylsilverlithium (I) at -60 and $-90^{\circ} \mathrm{C}$.

compound reveal the existence of different ortho protons at low temperatures as shown in Fig. 6. However, in this molecule diethyl ether is present, which may complicate the picture since the lithium-bound ether molecules might prefer certain configurational positions. Therefore, the observation of magnetically unequivalent ortho protons in this case may be caused both by nonplanarity of the $\mathrm{Ag}_{2} \mathrm{Li}_{2} \mathrm{C}_{4}$ ring system and/or by preferred configurations of the ether molecules.

In the non-symmetrically substituted compounds II and III the situation is even more complicated due to the additional possibility of configurational isomers arising from hindered rotation of the aryl groups around the $\mathrm{C}^{\mathbf{l}}-\mathrm{C}^{4}$ axis (cf. ref. 4). 'The spectra of these compounds do, indeed, show the presence of different ortho protons and of different methyl groups. However, the situation is too complicated to allow definite conclusions at present.

\section{Experimental}

\section{General}

All experiments were carried out under dry, oxygen-free nitrogen. Solvents were carefully purified, dried, and distilled before use under nitrogen. Solvents, solutions and liquid reagents were handled by syringes.

IR spectra were recorded on a Perkin-Elmer 457 infrared spectrometer using Nujol mulls between $\mathrm{KBr}$ disks. Frequencies are accurate to $\pm 3 \mathrm{~cm}^{-1}$.

NMR spectra were recorded on Varian EM-390 and XL-100/15 FT NMR spectrometers.

Decomposition temperatures were measured by differential thermal analysis and are accurate to $\pm 2^{\circ}$.

Elemental analyses have been carried out under the supervision of $\mathrm{Mr}$. W.J. Buis at the Analytical Department of the Institute for Organic Chemistry TNO, Utrecht. Because of the extreme sensitivity to air and moisture, however, the obtained analytical data have only an indicative value.

The arylsilver compounds were synthesized from the corresponding diarylzinc compounds and silver salts as described earlier [5,6].

The aryllithium compounds were synthesized by lithium-iodine exchange from butyllithium and the corresponding aryliodides [6]. The compounds were isolated by centrifugation since in some cases the precipitation occurred extremely slowly. 
Synthesis of the diethyl ether complexes of diphenylsilverlithium, bis(3-methylphenyl)silverlithium, and bis(4-methylphenyl)silverlithium

To a stirred suspension of $4.5 \mathrm{mmol}$ of phenylsilver, 3-methylphenylsilver, or 4-methylphenylsilver in $2 \mathrm{ml}$ of toluene, $4.5 \mathrm{mmol}$ of the corresponding aryllithium compound, dissolved in $5 \mathrm{ml}$ of diethyl ether, was slowly added at $-40^{\circ} \mathrm{C}$. After stirring for $10 \mathrm{~min}$ the ether was removed in vacuo $\left(-40^{\circ} \mathrm{C} / 1 \mathrm{~Pa}\right)$. The mixture was then warmed rapidly to $0^{\circ} \mathrm{C}$ to dissolve the precipitate. Immediately thereafter, the clear toluene solution was cooled to $-90^{\circ} \mathrm{C}$. During the cooling white crystals appeared. The supernatant liquor was decanted and the crystals were washed with $5 \mathrm{ml}$ of diethyl ether and $5 \mathrm{ml}$ of pentane at $-60^{\circ} \mathrm{C}$ and dried at $0^{\circ} \mathrm{C}$. In all cases, the yield was about $90 \%$.

Synthesis of the diethyl ether complex of bis(2-methylphenyl)silverlithium and the ether-free bis(2,6-dimethylphenyl)silverlithium

These compounds were prepared in the same way as the compounds mentioned above. However, it appeared that the yield decreased appreciably after washing with diethyl ether and, therefore, the products were washed with pentane only. It appeared that the 2,6-dimethylphenyl argentate contained no ether, in contrast to the 2-methylphenyl argentate. Attempts to isolate other argentates in an ether-free form by evacuation at temperatures of $0^{\circ} \mathrm{C}$ and above failed.

\section{Acknowledgements}

This investigation was supported by the Netherlands Foundation for Chemical Research (SON) with financial aid from the Netherlands Organisation for the Advancement of Pure Research (ZWO).

\section{References}

1 V.B. Smith and A.G. Massey, J. Amer. Chem. Soc., 23 (1970) C9.

2 A.J. Leusink, G. van Koten, J.W. Marsman and J.G. Noltes, J. Organometal. Chem., 55 (1973) 419.

3 D.H. Whiffen, J. Chem. Soe., (1956) 1350.

4 H.K. Hofstee, J. Boersma and G.J.M. van der Kerk, J. Organometal. Chem., 144 (1978) 255.

5 J. Boersma, F.J.A. des Tombe, F. Weyers and G.J.M. van der Kerk, J. Organometal. Chem., 124 (1977) 229.

6 H.K. Hoistee, J. Boersma and G.J. van der Kerk, J. Organometal. Chem., 168 (1979) 241.

7 M. Schlosser and V. Ladenberger, J. Organometal. Chem.. 8 (1967) 193. 